\title{
Social distance toward schizophrenia among parents of adolescents
}

\author{
Hatsumi Yoshii ${ }^{1^{*}}$, Yuichiro Watanabe ${ }^{2,3}$, Hideaki Kitamura ${ }^{2}$, Yiwei Ling ${ }^{4}$, Kouhei Akazawa ${ }^{4}$ \\ ${ }^{1}$ Faculty of Medicine, School of Health Sciences, Tohoku University, Miyagi, Japan; \\ *Corresponding Author: hatsumi@med.tohoku.ac.jp \\ ${ }^{2}$ Department of Psychiatry, Niigata University Graduate School of Medical and Dental Sciences, Niigata, Japan \\ ${ }^{3}$ Division of Medical Education, Comprehensive Medical Education Center, Faculty of Medicine, School of Medicine, Niigata Uni- \\ versity, Niigata, Japan \\ ${ }^{4}$ Department of Medical Informatics and Statistics, Graduate School of Medicine, Niigata University, Niigata, Japan
}

Received 7 April 2012; revised 24 April 2012; accepted 3 May 2012

\begin{abstract}
Social distance toward schizophrenia is a reason for delays in receiving early treatment for the disorder. This study attempted to identify the factors underlying social distance. The participants were 2690 parents of adolescents. Factor analysis using a social distance scale identified two factors: private relationship and social relationship. Regression analysis revealed that gender, age, and participation in welfare activities for people with mental illnesses had independent effects on the factor private relationship $(p<$ $0.05)$. These results suggest that women aged 40 - 49 years should be targeted for activities that attempt to counteract social distance and that they would benefit from taking part in public welfare activities for individuals with mental illnesses.
\end{abstract}

Keywords: Schizophrenia; Social Distance; Parents of Adolescents

\section{INTRODUCTION}

In the recent psychiatric literature, there has been an increasing focus on early detection and intervention for schizophrenia [1-3] Early detection and intervention can result in effective health management and improved quality of life $[1,4,5]$, while late detection and intervention are associated with lower quality of life and a need for costly residential healthcare $[6,7]$. One reason for delayed treatment is negative perceptions of schizophrenia [8-10]. Schizophrenia is associated with a number of negative associations [11-13], e.g., that recovery is impossible and that individuals with the disorder are dangerous or incompetent $[9,14,15]$. However, schizophrenia can be effectively treated [3,4]. In fact, early treat- ment can result in a satisfactory work and social life $[16,17]$. The negative image of schizophrenia is thus the greatest obstacle to improving the lives of people with schizophrenia and their families $[9,10,18]$. Therefore, improving understanding of schizophrenia and dispelling negative images toward the disorder are very important.

Because the opinions and behaviors of parents are very important in help-seeking, the present study investigated the parents of junior and senior high school students in Japan. Schizophrenia patients typically have difficulties in understanding their condition. Therefore, early treatment requires parental assistance. Parents with strong negative images of the disorder may not be open with and about their child and might not seek treatment.

We evaluated social distance toward schizophrenia among parents of adolescents. In addition, because of the importance of determining the characteristics of social distance associated with schizophrenia, we attempted to identify the most common forms of social distance toward schizophrenia so as to develop anti-stigma programs that target early intervention.

\section{PARTICIPANTS AND METHODS}

\subsection{Participants}

The participants were enrolled by a Japanese company specializing in research. A total of 2690 parents of junior and senior high school students completed a questionnaire, the details of which have been previously described [19]. The study was approved by the Ethics Committee of the Niigata University School of Medicine.

\subsection{Measurement}

The questionnaire asked about sociodemographic data such as area of residence, marriage status, and employment status and type. It also included items on attitudes toward schizophrenia, based on the Social Distance Scale- 
Japanese version (SDS-J) [20], which was adapted from the Whatley Social Distance Scale [21]. This scale consists of eight questions graded using a 4-point Likert scale ( 0 - 3 points), with higher scores representing increased social distance.

\subsection{Statistical Analysis}

All analyses were performed by using the Statistical Package for Social Sciences (SPSS) version 16.0. A p-value less than 0.05 was considered to indicate statistical significance, and all statistical tests were two-tailed. Factor analysis with the major factor method and Promax rotation was used to examine the factor structure of the Social Distance Scale. Cronbach's $\alpha$ was used to evaluate the reliability of scales with multiple items. Differences in the distributions of factor scores between categories were analyzed with the $t$ test when the factor had two categories and with ANOVA when it had more than two categories. Multiple regression analysis was used to examine the relative importance of different sociodemographic variables in predicting the factor scores.

\section{RESULTS}

\subsection{Participant Characteristics}

The participants were 2690 Japanese parents of junior and senior high school students (age range, 32 - 64 years). Area of residence was Kanto for 1069 (39.7\%) parents, Kinki for 496 (18.4\%), and Tokai for 327 (12.1\%). Regarding marriage status, 2552 (94.9\%) were married and $121(4.5 \%)$ were divorced. With regard to employment status, $1373(51.0 \%)$ were full-time employees and 542 (20.1\%) were housewives. A total of 2602 (96.7\%) respondents had no close relationship with someone with schizophrenia. Other details of the responses have been previously described [22].

\subsection{SDS-J Scores in Parents of Adolescents}

Mean score on the SDS-J was 12.1 (standard deviation $[\mathrm{SD}]=4.05)$, and the total score ranged from 0 to 24 . Cronbach's $\alpha$ for the SDS-J was high, at 0.849 . The median score was 11.92 , which indicates moderate social distance.

Results of factor analysis of the SDS-J revealed two factors with eigenvalues $\geq 1$. Factor 1 was private relationship (proportion of variance, $50.2 \%$; $\alpha$ coefficient, 0.82 ), and factor 2 was social relationship (proportion of variance, $12.72 \%$; $\alpha$ coefficient, 0.709 ), for a total variance of $16.3 \%$. The mean score was 8.60 for factor 1 (SD, 2.85; range, 0 - 15) and 3.47 for factor $2(\mathrm{SD}, 1.63$; range, 0 - 9; Table 1).

\subsection{SDS-J Factor 1 Scores and Demographic Factors}

The mean scores for factor 1 and related demographic factors are shown in Table 2. Gender was significantly associated with the score for factor 1 . Women had a higher score $(p<0.05)$. Regarding age, respondents aged 40 - 49 had the highest score $(p<0.05)$. Regarding employment status, participants with a side job had the highest score $(\mathrm{p}<0.05)$. With respect to occupation, re-

Table 1. Factor loading of social distance Scale-Japan (major factor method and Promax rotation).

\begin{tabular}{lc}
\hline Factor & Factor 1 Factor 2 \\
\hline No. of SDSJ item & 0.827 \\
\hline Factor 1: Private relationship & -0.062 \\
Q4. I would not ride in a taxi driven by someone with schizophrenia who had been in a mental hospital & 0.718 \\
Q5. I would rather not hire a person with schizophrenia who had been in a hospital & 0.148 \\
Q6. School teachers with schizophrenia who have been in a mental hospital should not be allowed to teach & 0.677 \\
Q8. I would be against any daughter of mine marrying a man with schizophrenia who had been in a hospital & 0.065 \\
Q7. If I needed a baby sitter, I would be willing to hire a woman with schizophrenia & -0.051 \\
Factor 2: Social relationship & -0.128 \\
Q1. It is best not to associate with a person with schizophrenia who had been in a mental hospital & 0.536 \\
Q3. It would bother me to live near a person with schizophrenia who had been in a mental hospital & 0.046 \\
Q2. It is wrong to shy away from a person with schizophrenia & 0.818 \\
Eigenvalue & 0.339 \\
Explained variance \% & 0.413 \\
$\alpha$ & -0.185 \\
\hline
\end{tabular}

Factor loadings $>0.5$ are used. Total variance, $16.373 \% ; \alpha=0.849$. SDSJ: Social Distance Scale-Japan. Q2 and Q7 were reversed items and were reversescored. 
Table 2. Factor scores in factor 1.

\begin{tabular}{|c|c|c|c|}
\hline & $\mathrm{n}$ & mean & $\mathrm{p}$ \\
\hline Gender & & & 0.002 \\
\hline Male & 1381 & 8.43 & \\
\hline Female & 1309 & 8.78 & \\
\hline Age, years & & & 0.003 \\
\hline $30-39$ & 221 & 8.56 & \\
\hline $40-49$ & 1904 & 8.72 & \\
\hline $50-59$ & 548 & 8.26 & \\
\hline $60-69$ & 17 & 7.41 & \\
\hline Employment status & & & 0.038 \\
\hline Full-time & 1373 & 8.52 & \\
\hline Part-time & 461 & 8.72 & \\
\hline Self-employed/housework/libelal profession & 259 & 8.81 & \\
\hline Side job & 10 & 9.20 & \\
\hline Full-time homemaker & 542 & 8.70 & \\
\hline Unemployed & 34 & 7.21 & \\
\hline Other & 11 & 7.82 & \\
\hline Occupation & & & 0.030 \\
\hline Agriculture & 10 & 8.60 & \\
\hline Forestry & 0 & - & \\
\hline Fisheries & 1 & - & \\
\hline Mining & 2 & 8.50 & \\
\hline Construction & 144 & 8.47 & \\
\hline Industry & 454 & 8.45 & \\
\hline Electricity/gas/heat/water & 31 & 8.29 & \\
\hline Information/correspondence & 70 & 8.07 & \\
\hline Transportation & 71 & 8.24 & \\
\hline Distributor/retailer & 194 & 8.84 & \\
\hline Finance/insurance & 116 & 9.01 & \\
\hline Real estate & 39 & 9.00 & \\
\hline Restaurant/lodging & 58 & 8.76 & \\
\hline Medicine/welfare & 194 & 9.32 & \\
\hline Education/learning support & 144 & 8.06 & \\
\hline Mixed & 5 & 9.80 & \\
\hline Service & 282 & 8.62 & \\
\hline Official duty & 144 & 8.32 & \\
\hline Others & 155 & 8.64 & \\
\hline Family income, yen & & & 0.002 \\
\hline$<1$ million & 41 & 9.10 & \\
\hline 1 million to 3 million & 196 & 8.62 & \\
\hline 3 million to 5 million & 502 & 8.47 & \\
\hline 5 million to 10 million & 1465 & 8.48 & \\
\hline$>10$ million & 486 & 9.06 & \\
\hline Participation in welfare activities for people with mental illnesses & & & 0.001 \\
\hline Yes & 222 & 8.01 & \\
\hline No & 2468 & 8.65 & \\
\hline t-test, ANOVA & & & \\
\hline
\end{tabular}


spondents who answered "mixed" had the highest score $(\mathrm{p}<0.05)$. In addition, people in families earning less than 1 million yen per year had the highest score $(p<$ 0.05 ). Respondents were asked whether they participated in welfare activities for people with mental illnesses, and those who had not participated in such activities scored higher than those who had $(\mathrm{p}<0.05)$.

Multiple regression analysis revealed that gender, age and participation in welfare activities for people with mental illnesses were significantly associated with factor 1 ( $\mathrm{p}<0.05$; Table 3).

\section{DISCUSSION}

In Japan, 333,000 people were hospitalized for mental illness in 2008 [23]. In the past, the government kept such patients in isolation, which led to international criticism. The transition from an institution-based to a community-based mental care system was formally initiated by the "Law Related to Mental Health and Welfare of Persons with Mental Disorders" of 1999. However, support after discharge from mental hospitals was not included in the legislation, which partially explains why many Japanese have a negative image of mental illness [24]. These negative attitudes toward mental illness affect patient quality of life and treatment. Thus, combating unfavorable images of people with mental illness is essential [15,25-28]. In 1996, the World Psychiatric Association began its Open the Door anti-stigma campaign [11]. In Japan, it was promoted in a number of areas, including the cities of Obihiro, Sendai, Okayama, and Ichikawa. We surveyed the present population because it was not included in the Open the Door campaign. We hope that our findings will help people at risk of mental illness.

There are two types of stigma scales. One measures social stigma, e.g., Link's Devaluation-Discrimination Measure. The Devaluation-Discrimination Measure asks respondents to evaluate statements such as "most people would accept a person with schizophrenia as a close friend" or "most young women would be reluctant to date a man who has schizophrenia". Other instruments assess individual stigma, e.g., the Social Distance Scale. It includes statements such as "It is wrong to shy away from a person with schizophrenia" or "If I needed a baby sitter, I would be willing to hire a woman with schizophrenia". We examined social distance toward schizophrenia. In our study, two factors were revealed by factor analysis of the Social Distance Scale: private relationship and social relationship. The former was of particular interest because this scale measures individual stigma (factor 1). The results showed that lack of participation in public welfare activities for individuals with mental illnesses was associated with greater social distance $(\mathrm{p}<$ $0.05)$. In contrast, we previously found that social stigma was significantly greater among those who participated in public welfare activities for individuals with mental illnesses [19]. That is to say, lack of participation in public welfare activities for people with mental illnesses was the largest contributor to stigma for the individual, while participation in public welfare activities resulted in the greatest stigma in social relationship. These results are similar those reported in a study by Tania [29], which investigated implicit and explicit attitudes to schizophrenia.

We investigated private relationships. The results suggest that it is necessary to develop measures to address social distance toward schizophrenia among Japanese women aged 40 - 49 years and to encourage them to participate in public welfare activities. We caught focus target. Provision of stigma by private relationship is a social activity. We must plan public campaigns that encourage busy mothers of adolescents to take part in welfare activities. Finally, we hope that similar investigations will be conducted in other countries.

\section{ACKNOWLEDGEMENTS}

This work was supported by a 2010 Grant-in-Aid for Scientific Research (C) from the Japan Society for the Promotion of Science (22592581) entitled Investigations of the Consciousness of Parents of Junior and Senior High School Students Concerning Schizophrenia and

Table 3. Results of multiple regression analysis of factor 1 and factor 2 as dependent variables $(n=2690)$.

\begin{tabular}{|c|c|c|c|c|c|c|}
\hline \multirow[b]{2}{*}{ Variable } & \multicolumn{3}{|c|}{ Factor 1} & \multicolumn{3}{|c|}{ Factor 2} \\
\hline & $\beta$ & $\mathrm{t}$ & $\mathrm{p}$ & $\beta$ & $\mathrm{t}$ & $\mathrm{p}$ \\
\hline Gender & 0.060 & 3.135 & 0.002 & -0.045 & -2.352 & 0.019 \\
\hline Age & -0.053 & -2.746 & 0.006 & 0.002 & 0.121 & 0.904 \\
\hline Employment status & 0.008 & 0.437 & 0.662 & -0.044 & -2.264 & 0.024 \\
\hline Marital status & -0.013 & -0.657 & 0.511 & -0.040 & -2.075 & 0.038 \\
\hline Welfare activities for people with mental illness & 0.062 & 3.230 & 0.001 & 0.099 & 5.141 & 0.001 \\
\hline
\end{tabular}

$\beta$ : standardized regression coefficient; t: t-value; R: multiple correlation coefficients. 
the Development of Educational Enlightenment Media.

\section{REFERENCES}

[1] Johnstone, E.C., Crow, T. J., Johnson, A.L. and MacMillan J.F. (1986) The Northwick Park Study of first episodes of schizophrenia. I. Presentation of the illness and problems relating to admission. British Journal of Psychiatry, 148, 115-120.doi:10.1192/bjp.148.2.115

[2] Compton, M.T. (2004) Considering schizophrenia from a prevention perspective. American Journal of Preventive Medicine, 26, 178-185. doi:10.1016/j.amepre.2003.10.003

[3] Chong, S.A., Lee, C., Bird, L. and Verma, S. (2004) A risk reduction approach for schizophrenia: The Early Psychosis Intervention Programme. Annals Academy of Medicine Singapore, 33, 630-635.

[4] Loebel, A.D., Lieberman, J.A., Alvir, J.M., Mayerhoff, D.I., Geisler, S.H. and Szymanski, S.R. (1992) Duration of psychosis and outcome in first-episode schizophrenia. American Journal of Psychiatry, 149, 1183-1188.

[5] Helgason, L. (1990) Twenty years' follow-up of first psychiatric presentation for schizophrenia: What could have been prevented? Acta Psychiatry Scand, 81, 231-235. doi:10.1111/j.1600-0447.1990.tb06486.x

[6] Papadopoulos, C., Leavey, G. and Vincent, C. (2002) Factors influencing stigma: A comparison of Greek-Cypriot and English attitudes towards mental illness in north London. Social Psychiatry Psychiatric Epidemiology, 37, 430-434. doi:10.1007/s00127-002-0560-9

[7] Yoshii, H., Watanabe, Y., Kitamura, H., Nan, Z. and Akazawa, K. (2012) Effect of an education program on improving help-seeking among parents of junior and senior high school students in Japan. Global Journal of Health Science, 4, 33-41.

[8] Tanaka, G., Ogawa, T., Inadomi, H., et al. (2003) Effects of an educational program on public attitudes towards mental illness. Psychiatry and Clinical Neurosciences, 57, 595-602. doi:10.1046/j.1440-1819.2003.01173.x

[9] Lysaker, P.H., Davis, L.W., Warman, D.M., Strasburger, A. and Beattie, N. (2007) Stigma, social function and symptoms in schizophrenia and schizoaffective disorder: Associations across 6 months. Psychiatry Research, 149, 8995. doi:10.1016/i.psychres.2006.03.007

[10] Esterberg, M.L., Compton, M.T., McGee, R., Shim, R. and Hochman, K. (2008) Knowledge about schizophrenia and social distance toward individuals with schizophrenia: A survey among predominantly low-income, urban, African American community members. Journal of Psychiatric Practice, 14, 86-93. doi:10.1097/01.pra.0000314315.94791.80

[11] Kadri, N. and Sartorius, N. (2005) The global fight against the stigma of schizophrenia. PLoS Medicine, 2, e136. doi:10.1371/journal.pmed.0020136

[12] Heather, S. and Arboleda-Florez, J. (2001) Community attitudes toward people with schizophrenia. Canadian Journal of Psychiatry, 46, 245-251.

[13] Corrigan, P.W., Edwards, A.B., Green, A., Diwan, S.L. and Penn, D.L. (2001) Prejudice, social distance, and fa- miliarity with mental illness. Schizophrenia Bulletin, 27, 219-225. doi:10.1093/oxfordjournals.schbul.a006868

[14] Angermeyer, M.C., Matschinger, H. and Corrigan, P.W. (2004) Familiarity with mental illness and social distance from people with schizophrenia and major depression: Testing a model using data from a representative population survey. Schizophrenia Research, 69, 175-182. doi:10.1016/S0920-9964(03)00186-5

[15] Ertugrul, A. and Ulug, B. (2004) Perception of stigma among patients with schizophrenia. Social Psychiatry Epidemiology, 39, 73-77.

[16] de Koning M.B., Bloemen, O.J.N., van Amelsvoort, T.A.M.J., Becker, H.E., Nieman, D.H., van der Gaag, M. and Linszen, D.H. (2009) Early intervention in patients at ultra high risk of psychosis: Benefits and risks. Acta Psychiatrica Scandinavica, 119, 426-442. doi:10.1111/j.1600-0447.2009.01372.x

[17] Yoshii, H., Watanabe, Y., Kitamura, H., Chen, J. and Akazawa, K. (2011) Effect of an education program on improving knowledge of schizophrenia among parents of junior and senior high school students in Japan. $B M C$ Public Health, 11, 323. doi:10.1186/1471-2458-11-323

[18] Lauber, C., Anthony, M., Ajdacic-Gross, V. and Rossler, W. (2004) What about psychiatrists' attitude to mentally ill people? European Psychiatry, 19, 423-427. doi:10.1016/j.eurpsy.2004.06.019

[19] Yoshii, H., Watanabe, Y., Kitamura, H., Nan, Z. and Akazawa, K. (2011) Stigma toward schizophrenia among parents of junior and senior high school students in Japan. BMC Research Notes, 4, 558. doi:10.1186/1756-0500-4-558

[20] Makita, K. (2006) Development and reliability of the Japanese language version of Social Distance Scale (SDSJ). Japanese Bulletin of Social Psychiatry, 14, 231-241.

[21] Whatley, C. (1959) Social attitudes towards discharge mental patients. Social Problems, 6, 313-320. doi:10.1525/sp.1959.6.4.03a00050

[22] Yoshii, H., Watanabe, Y., Kitamura, H., Chen, J. and Akazawa, K. (2011) Effect of an education program on improving knowledge of schizophrenia among parents of junior and senior high school students in Japan. BMC Public Health, 11, 323. doi:10.1186/1471-2458-11-323

[23] Ministry of Health, Labour and Welfare. http://www.mhlw.go.jp/seisakunitsuite/bunya/hukushi kaig o/shougaishahukushi/kaigi shiryou/d1/20110927 04.pdf

[24] Tanaka, G. (2004) Evaluating stigma against mental disorder and related factors. Psychiatry and Clinical Neurosciences, 58, 58-66. doi:10.1111/j.1440-1819.2004.01300.x

[25] Alison, J.G. and MRCPsych (2002) Stigma in psychiatry. Journal of the Royal Society Medicine, 95, 72-76. doi:10.1258/jrsm.95.2.72

[26] Jo, C.P., Evelyn, J.B. and Bruce, G.L. (1998) Psychiatric illness and family stigma. Schizophrenia Bulletin, 24, 115-126. doi:10.1093/oxfordjournals.schbul.a033304

[27] Blignault, I., Woodland, L., Ponzio, V., Ristevski, D. and Kirov, S. (2009) Using a multifaceted community intervention to reduce stigma about mental illness in an Aus- 
tralian Macedonian community. Health Promotion Journal of Australia, 20, 227-233.

[28] Patrick, W.C., Jonathon, L., Molly, S., Nathaniel, N. and Amy, C.W. (2007) Will filmed presentations of education and contact diminish mental illness stigma? Community Mental Health Journal, 43, 171-181. doi:10.1007/s10597-006-9061-8

[29] Lincoln, T.M., Arens, E., Berger, C. and Rief, W. (2008) Can antistigma campains be improved? A test of impact of biogenetic vs psychosocial causal explanations on implicit and explicit attitudes to schizophrenia. Schizophrenia Bulletin, 34, 984-994. doi:10.1093/schbul/sbm131 